\title{
Verhältnismäßigkeit im Völkerrecht
}

\author{
Hrsg. v. Björnstjern Baade, Sebastian Ehricht, Matthäus Fink, Robert Frau, Mirka \\ Möldner, Isabella Risini u. Torsten Stirner
}

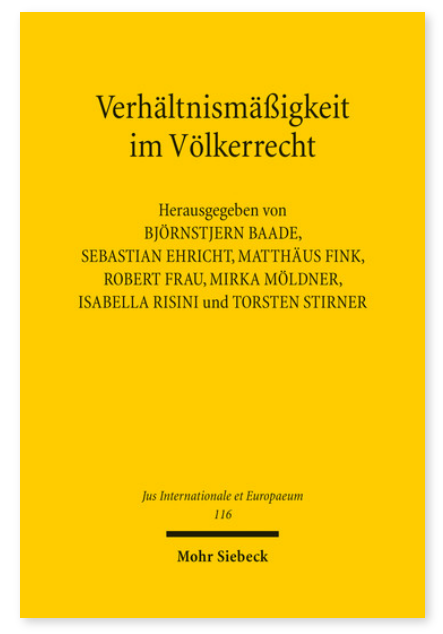

2016. X, 174 Seiten. JusIntEu 116

ISBN 978-3-16-154244-2

DOI 10.1628/978-3-16-154244-2

eBook PDF 64,00€

ISBN 978-3-16-154243-5

fadengeheftete Broschur $64,00 €$
Das Prinzip der Verhältnismäßigkeit erhält in verschiedenen Bereichen des Völkerrechts Aufmerksamkeit und Relevanz. Dies war Anlass für den Arbeitskreis junger Völkerrechtswissenschaftler*innen und die Deutsche Gesellschaft für Internationales Recht, gemeinsam einen Blick auf dieses Prinzip zu werfen. Der daraus entstandene Tagungsband liefert Einsichten aus diversen Blickwinkeln: Er stellt allgemeine gebietsübergreifende Fragen, etwa ob Verhältnismäßigkeit als globales Verfassungsprinzip verstanden und als Mittel zur Harmonisierung und Defragmentierung nutzbar gemacht werden kann. Darüber hinaus enthält der Band philosophische Grundüberlegungen. Es werden die Relevanz und Wirkungsweise in verschiedenen konkreten Teilgebieten wie dem humanitären Völkerrecht und dem Menschenrechtsschutz untersucht. Auch aktuelle Fragen internationaler Schiedsgerichtsbarkeit werden kritisch aufgegriffen. Nicht zuletzt setzen sich die Beiträge mit der aktuellen Rechtsprechung des Europäischen Gerichtshofes zur Verhältnismäßigkeit als Kompetenzregulativ auf Unionsebene auseinander.

Inhaltsübersicht

Anne Peters: Verhältnismäßigkeit als globales Verfassungsprinzip - Frederik Becker: Jurisdiktion und Verhältnismäßigkeit, Gewährleistungsumfang und Modifikationen der Menschenrechte bei extraterritorialen Sachverhalten - Sebastian Wuschka: Proportionality reloaded - Autonom agierende Drohnen und der Verhältnismäßigkeitsgrundsatz des Humanitären Völkerrechts - Thomas Müller: Abwägung von Menschenleben im Völkerrecht - Sué González Hauck: Normenkonflikte als Optimierungsprobleme? Kritik am Einsatz des Verhältnismäßigkeitsprinzips als Mittel zur Harmonisierung des Völkerrechts Rike Sinder: Verhältnismäßigkeit, Dekonstruktion, Gerechtigkeit. Zugleich eine Erwiderung auf Martti Koskenniemis postmoderne Kritik in From Apology to Utopia - Michael Goldhammer: Kritik und Rekonstruktion kompetenzbezogener Verhältnismäßigkeit im Unionsorganisationsrecht - Lars Schönwald: Der Verhältnismäßigkeitsgrundsatz im Recht der Auslandsinvestitionen unter Berücksichtigung der Änderungen durch den Lissabon-Vertrag

Björnstjern Baade Geboren 1984; Studium der Rechtswissenschaft an der Freien Universität Berlin und der University of Birmingham (UK); seit 2012 Wissenschaftlicher Mitarbeiter am Lehrstuhl für Öffentliches Recht und Völkerrecht (FU Berlin); Referendariat am Kammergericht Berlin; 2016 Zweite Juristische Staatsprüfung und Promotion; 2022 Habilitation. https://orcid.org/0000-0001-7563-4065

Sebastian Ehricht ist Doktorand am Lehrstuhl für Öffentliches Recht, insb. Völkerrecht, der Georg-August-Universität Göttingen.

Matthäus Fink ist Doktorand am Lehrstuhl für Öffentliches Recht, insb. Völkerrecht, der Georg-August-Universität Göttingen.

Robert Frau Geboren 1979; Studium der Rechtswissenschaften an der Europa-Universität Viadrina in Frankfurt (Oder); 2005 Erstes Juristisches Staatsexamen; 2010 Promotion; Rechtsreferendariat in Berlin und New York; 2010 Zweites Juristisches Staatsexamen; Akademischer Mitarbeiter an der Viadrina; 2019 Habilitation und Ernennung zum Privatdozenten ebendort; seit 2017 Lehrstuhlvertretungen an den Universitäten Leipzig, Potsdam, FU Berlin, Marburg und Heidelberg.

Mirka Möldner ist Doktorandin am Max-Planck-Institut für ausländisches öffentliches Recht und Völkerrecht, Heidelberg.

Isabella Risini ist Akademische Rätin auf Zeit an der Juristischen Fakultät der Ruhr-Universität Bochum. https://orcid.org/0000-0002-6151-8650

Torsten Stirner ist Doktorand am Lehrstuhl für Öffentliches Recht, Völkerrecht und Menschenrechte der Georg-AugustUniversität Göttingen.

Jetzt bestellen:

https://mohrsiebeck.com/buch/verhaeltnismaessigkeit-im-voelkerrecht-9783161542442?no_cache=1

order@mohrsiebeck.com

Telefon: +49 (0)7071-923-17

Telefax: $+49(0) 7071-51104$ 